Relations industrielles

Industrial Relations

\title{
Science and Society, The Meaning and Importance of Scientific Method, by Michael Bassey, London, The University of London Press Ltd., 1968, 96 pp.
}

\section{Jean Bernier}

Volume 26, numéro 2, 1971

URI : https://id.erudit.org/iderudit/028240ar

DOI : https://doi.org/10.7202/028240ar

Aller au sommaire du numéro

Éditeur(s)

Département des relations industrielles de l'Université Laval

ISSN

0034-379X (imprimé)

1703-8138 (numérique)

Découvrir la revue

Citer ce compte rendu

Bernier, J. (1971). Compte rendu de [Science and Society, The Meaning and Importance of Scientific Method, by Michael Bassey, London, The University of London Press Ltd., 1968, 96 pp.] Relations industrielles / Industrial Relations, 26(2), 518-518. https://doi.org/10.7202/028240ar

Tous droits réservés @ Département des relations industrielles de l'Université Laval, 1971
Ce document est protégé par la loi sur le droit d'auteur. L’utilisation des services d'Érudit (y compris la reproduction) est assujettie à sa politique d'utilisation que vous pouvez consulter en ligne.

https://apropos.erudit.org/fr/usagers/politique-dutilisation/ 
5. Les conditions à réunir pour une bonne séance;

6. Préparation et rangement du matériel de présentation.

Les sujets étudiés sont multiples et variés. Certaines parties sont techniques, d'autres théoriques. En fait, un technicien du matériel audiovisuel sera toutà-fait à son aise dans les premières mais s'il veut élargir ses connaissances et rejoindre les préoccupations du formateur il aura grand profit à lire les parties qui à prime abord intéresseront surtout celui-ci.

Pour le non-initié aux deux aspects de la question, ce volume est beaucoup plus qu'une introduction au sujet et son étude, sans en faire un expert, lui permettra de se sentir beaucoup plus à l'aise face à cette matière.

Personnellement, les deux premières sections nous sont apparues particulièrement intéressantes parce que l'auteur a très bien su situer d'une part le problème de la formation dans l'entreprise et d'autre part, le phénomène de résistance ou de réticence face à l'emploi de l'audiovisuel à l'intérieur des programmes de formation. A notre avis, une lecture de ces pages et une réflexion sérieuse peuvent sinon convaincre, du moins amener à tenter un essai le plus acharné adversaire.

Dans le contexte des entreprises québecoises, le recours à l'audiovisuel en formation est peu répandu. Par son ouvrage, Rigg nous fait découvrir tous les avantages qu'on peut en retirer et aussi il nous indique les instruments et les techniques à utiliser selon les objectifs visés, les moyens et le temps dont on dispose. Les illustrations sont nombreuses il va sans dire: dessins, photos, tables techniques...

Il est un reproche que nous pouvons faire à l'éditeur français : celui de s'être limité aux ouvrages et revues françaises dans sa bibliographie et sources de documentation qu'il présente à la fin du volume. Enfin une réserve face au lexique audiovisuel bilingue présenté en annexe et qui n'est pas complet; plusieurs termes techniques employés fréquemment en anglais tout au long de l'ouvrage ne s'y retrouvent pas.

Cependant il ne faut pas s'attarder sur ces détails mais retenir l'essentiel et l'ensemble de l'ouvrage même de Rigg qui est sans contredit excellent.

Jean-Pierre BEAULIEU
Science and Society, The Meaning and Importance of Scientific Method, by Michael Bassey, London, The University of London Press Ltd., 1968, 96 pp.

Ce petit livre présente un essai à caractère philosophique sur les principes qui sous-tendent la méthode scientifique appliquée à la solution de problèmes sociaux.

Il invite à la réflexion sur les limites d'une telle méthode.

Son principal mérite réside selon nous dans l'insistance de l'auteur sur l'importance de la distinction entre les faits, les valeurs et les hypothèses et sur la dissociation du chercheur de l'objet de son étude.

Notons que l'ouvrage est abondamment illustré et qu'il comporte de nombreux exemples d'application de la méthode scientifique à des problèmes contemporains tels que l'usage de la cigarette et le cancer, la carie dentaire et la fluoration de l'eau, le crime et la sanction, etc.

S'il ne s'agit pas d'un livre qui a principalement pour objet d'enseigner la méthode scientifique, il invite à la réflexion sur les limites d'une telle méthode.

Jean BERNIER

Western European Labor and the American Corporation, by Alfred Kamin, Ed., Washington, D.C., Bureau of National Affairs, 1970, $546 \mathrm{pp}$.

Sous ce titre, cet ouvrage présente une vingtaine d'études diverses dont le moins qu'on puisse dire, c'est qu'elles sont intéressantes et utiles. Elles traitent de huit thèmes principaux : 1. la sociśté ou l'entreprise multinationale ; 2 . la politique sociale de la communauté économique européenne; 3 . les conflits de travail et la négociation collective dans les pays de l'Europe de l'Ouest; 4. les relations de travail et la législation du travail en différents pays du vieux continent ; 5. la fixation des salaires et des avantages sociaux ; 6. l'utilisation, la mobilité et la formation de la main-d'œuvre; 7. le management et la politique d'investissement en Europe de l'Ouest; 8. les relations de travail et le défi démocratique.

Il n'est pas possible dans une recension de quelques pages d'analyser tous les sujets qu'on trouve ici exposés. Il ne 